\title{
From Social Determinants of Health Actions to Fight against the Lassa Virus Hemorrhagic Fever Epidemic in Tchaourou Commune in Benin, 2018
}

\author{
Luc Béhanzin*, Thierry Adoukonou, David Houeto, Covalic Bokossa, Maurice Agonnoude \\ School of Public Health and Epidemiology, University of Parakou, Parakou, Bénin \\ Email: ^bphilus2013@gmail.com
}

How to cite this paper: Béhanzin, L., Adoukonou, T., Houeto, D., Bokossa, C. and Agonnoude, M. (2019) From Social Determinants of Health Actions to Fight against the Lassa Virus Hemorrhagic Fever Epidemic in Tchaourou Commune in Benin, 2018e. Open Journal of Epidemiology, 9, 1-14.

https://doi.org/10.4236/ojepi.2019.91001

Received: November 14, 2018

Accepted: December 4, 2018

Published: December 7, 2018

Copyright $\odot 2019$ by authors and Scientific Research Publishing Inc. This work is licensed under the Creative Commons Attribution International License (CC BY 4.0).

http://creativecommons.org/licenses/by/4.0/

\begin{abstract}
Background: Lassa Hemorrhagic Fever (LHF) is endemo-epidemic in West Africa with seasonal outbreaks raising a major public health issue. Nigeria borders Benin by the Tchaourou Commune. Since 2016, Tchaourou commune has been affected every year by this epidemic. Objective: To study how an action on the health social determinants can contribute to ending this epidemic in Tchaourou commune, Benin. Methods: This cross-sectional study was conducted in Tchaourou commune. All of the cases of LHF occurring in 2016-2018 were retrospectively tracked throughout the commune. The health workers and 172 participants of the general population of villages of the cases were enrolled. We used absolute frequency to describe the LHF cases because of their small number. The descriptive analyses were performed using EPI-INFO 7.1.14. Results: Overall, 27 cases of LHF occurred in Tchaourou. In these 27 cases, 12 were Laboratory-Confirmed. All 4 probable cases died while $42 \%$ and $18 \%$ died in the confirmed and suspected cases, respectively. Most (75\%) of the cases were female. By direct observations, the commune had a weak health-promoting environment for fighting against LHF outbreak. According to the health care staff in the commune, the interventions were for controlling the outbreak and not the promoting interventions to preventing further outbreaks. Conclusion: To fight effectively against the Lassa fever, it is necessary to act on different social determinants of health with community participation, empowerment and health control. The fight against Lassa fever remains a major challenge facing developing countries like Benin.
\end{abstract}

\section{Keywords}

Lassa Hemorrhagic Fever, Health Promotion, Social Determinants 


\section{Introduction}

Lassa virus has been known since 1950s, but the virus has not been identified until 1969 when one missionary nurse, posted by the Church of the Brethren in the USA, to the local hospital in Lassa town, died from an outbreak in the Lassa town hospital caused by a virus firstly isolated in this hospital then called Lassa virus [1] [2]. The Lassa Hemorrhagic Fever (LHF) was reported as severe, often fatal disease occurring in Africa and resulting from infection by an arenavirus [1]. The disease is endemic in West Africa and affects every year from 100,000 to 300,000 people in West Africa with a Case Fatality Rate (CFR) being able to reach 15\% [2] [3] [4]. In West Africa, the outbreak has spread in Nigeria and occurred in Liberia, Sierra Leone, Guinea, Ghana, Ivory Coast, Senegal and Mali so far. And it appeared in Benin in November 2014. After the investigation in Sierra Leone in 1972, the natural reservoir of Lassa was identified as the multimammate rodent Mastomys natalensis [1] [5]. The Lassa virus isolation is best accomplished from serum obtained during the first 2 weeks of illness [6]. Since 2014, there has been Lassa fever outbreak every year in Benin within the period October-April like that of Nigeria where usually comes the index case of Benin. Indeed, in 2018 the first case in Benin who had come from Nigeria was admitted on 8 January 2018 at Saint Jean de Dieu hospital in Tanguieta in Benin with symptoms including high grade fever, haematemesis, bleeding gums, conjunctivitis and abdominal pain [4] [7] [8].

The virus spread is from rodents to human through contact with rodents' excreta or urine in food or during hunting and processing of rodents for consumption. The virus can spread from person to person, either within households during care provision for sick relatives or in health care settings [9].

Then the public health approach is used for controlling the outbreak like intensification of risk communication and social activities in the affected communities and sensitization on Lassa fever prevention and control measures by traditional healers and community leaders in the affected communities [7]. But as we know the dynamics and mode of transmission of Lassa fever [10], we need holistic intervention of the integrated promotion and prevention strategies with public health approaches to halting transmission and preventing further outbreaks at the source. We could overcome with health equity, the change of social (including environment) context that influences health. Since 2016, Tchaourou commune has been affected every year by this epidemic. It's why we aim to study how an action on the health social determinants can contribute to ending this epidemic in Tchaourou commune.

\section{Methods}

\subsection{Study Settings}

This cross-sectional study was conducted in Tchaourou commune, a rural district of Borgou department, specifically in the "Saint Martin de Papane" hospital which is the Tchaourou district Hospital, in the primary health centre of 
Tchaourou commune, Tchaourou district office and in the Tchaourou community also.

\subsection{Sampling, Recruitment and Data Collection}

Three groups of targeted population were included in the study: All of the cases of LHF occurred in the Tchaourou commune in 2016-2018 (targeted population level 1), all of the public health workers in Tchaourou Health Zone and agents of the zone office (targeted population level 2), and the general population of villages from which LHF cases emerged in the Tchaourou commune (targeted population level 3).

\subsection{Eligibility Criteria}

All of the health workers who consented to participate in the study were included in it. For the general population, participants were eligible for the study if they were 18 years or older. Apart from obtaining the verbal informed consent from any participant, the participant of general population of villages from which the cases emerged who did not have their all mental capacity to answer validly the questions was excluded from the study.

For the general population, the minimized sample size was calculated using the formula of Schwartz increased by $10 \%$ for preserving statistical power because of refusal to participate in the study. We used a random route sampling procedure [11] to select the participants in the general population (five villages from which the LHF cases emerged).

A Form of data reduction was used to collect case data in the hospitals and structured-questionnaire was used to collect data in the general population and from health workers. Observation guide was used for collecting data on behaviors and lifestyle, the environment and the organization of the health system in the commune mainly in the 5 villages from which LHF cases emerged.

\subsection{Statistical Analyses}

Data were double entered with EPI-INFO Epi-Info 7.1.14 (CDC, Atlanta, Georgia, USA) for controlled data treatment, and descriptive analyses were performed using this software. Excel 2010 (Microsoft Office) was used for describing qualitative characteristics by table of proportions. The quantitative variables were described using mean and standard error. The distribution of the LHF cases was performed using absolute frequency because of their small number.

\section{Ethical Considerations}

Verbal informed consent was obtained from each of the participants in the study. The study was approved by the ethics committee of the University of Parakou, Benin.

\section{Results}

Overall, throughout the three episode epidemic years, 27 cases of LHF occurred 
in Tchaourou. Of these 27 cases, 12 were Laboratory-Confirmed LHF including one 4-month-old baby, 11 were suspected cases and four (04) were probable cases (suspect accommodates who has the epidemiological link to year has confirmed compartment). All 4 probable cases died while $42 \%$ (5/12) and 18\% $(2 / 11)$ died in the confirmed cases and suspected cases, respectively (Table 1). One in two of the cases were adults from 20 to 30 years old and there was a 4-month-old baby in the retrospective case series (Table 1). Most of the cases (9/12) were female (75\%). Among the adult cases, 36.4\% (4/11) were health workers. The epidemic episode of 2016 more raged with more occurred cases and deaths (Table 2).

Of 12 confirmed LHF cases, 10 cases, 01 case and 01 case occurred in Tchaourou, in 2016, 2017 and 2018, respectively (Table 2).

The frequency of symptoms and signs is shown in Table 2 . These clinical features include mainly fever, headache, vomiting, diarrhea, tiredness, anorexia, cough and muscular pain.

In the general population from where emerged the cases, participants were $62.8 \%$ men with the mean age at $29.9 \pm 8.4$ years and the $18-33$ years old predominated (65\%). Overall, 64 of participants (37.2\%) were illiterate. Most of them (81.4\%) were married (Table 3). There was a poor level of knowledge on LHF in 120 of participants (69.8\%) and none of the participants reached a good level of knowledge of LHF (Table 3).

According to the health workers in the commune, before the outbreak, beside active surveillance of LHF cases and report of cases to a lesser extent, through the directives that must be taken no other one is taken. To a large extent, it is about interventions of controlling the outbreak and not the promoting intervention to preventing further outbreaks (Table 4).

To better evaluate the social determinants leading to the emergence of LHF in the five different villages/neighborhoods from which the Lassa cases in the commune of Tchaourou emerged, we made direct observations of its various determinants, which are grouped into three major groups to know the Behaviors and lifestyle, the environment and the organization of the health system.

In the Tchaourou commune, the main observed facilitating factors of the occurrence of LHF outbreak were consumption of mice, consumption of wild

Table 1. Distribution of Lassa hemorrhagic fever cases by year, from 2016 to 2018 in Tchaourou commune, Benin, 2018.

\begin{tabular}{cccccccc}
\hline \multirow{2}{*}{ Year } & \multicolumn{2}{c}{ Suspected cases } & \multicolumn{2}{c}{ Probable cases* } & \multicolumn{2}{c}{ Confirmed cases } & \multirow{2}{*}{ TOTAL } \\
\cline { 2 - 7 } & Alive & Died & Alive & Died & Alive & Died & \\
\hline 2016 & 3 & 2 & 0 & 4 & 7 & 3 & 19 \\
2017 & 1 & 0 & 0 & 0 & 0 & 1 & 2 \\
2018 & 5 & 0 & 0 & 0 & 0 & 1 & 6 \\
TOTAL & 9 & 2 & 0 & 4 & 7 & 5 & 27 \\
\hline
\end{tabular}

${ }^{*}$ A case that meets the clinical case definition, is not laboratory confirmed, but has an epidemiological link to a confirmed case. 
Table 2. Characteristics of confirmed Lassa hemorrhagic fever cases occurred from 2016 to 2018 in Tchaourou commune, Benin, 2018.

\begin{tabular}{|c|c|}
\hline Characteristics & Number \\
\hline Age (year) & $\mathrm{N}=12$ \\
\hline$<20^{\star}$ & 1 \\
\hline $20-30$ & 6 \\
\hline $30-40$ & 3 \\
\hline $40-50$ & 2 \\
\hline Sex & $\mathrm{N}=12$ \\
\hline Female & 9 \\
\hline Male & 3 \\
\hline Profession ${ }^{\star}$ & $\mathrm{N}=11$ \\
\hline Health personnel & 4 \\
\hline Trader & 2 \\
\hline housewife & 5 \\
\hline Location & $\mathrm{N}=12$ \\
\hline Kassouala & 2 \\
\hline Papane & 5 \\
\hline Tchaourou & 2 \\
\hline Tchatchou & 2 \\
\hline Tekparou & 1 \\
\hline Place of hospitalization & $\mathrm{N}=12$ \\
\hline CHUD-B $^{*}$ & 5 \\
\hline $\mathrm{HZSP}^{\star *}$ & 7 \\
\hline Year of occurrence & $\mathrm{N}=12$ \\
\hline 2016 & 10 \\
\hline 2017 & 1 \\
\hline 2018 & 1 \\
\hline Signs and symptoms shown & $\mathrm{N}=12$ \\
\hline Fever & 12 \\
\hline Headache & 10 \\
\hline Cough & 6 \\
\hline Diarrhea & 8 \\
\hline Rash & 2 \\
\hline Abdominal pain & 3 \\
\hline Bleeding & 5 \\
\hline Vomiting & 10 \\
\hline Fatigue/tiredness & 11 \\
\hline Anorexia & 11 \\
\hline Muscular pain & 6 \\
\hline Dyspahasia & 3 \\
\hline Dyspnoea & 3 \\
\hline
\end{tabular}

${ }^{\star}$ One case of a four-months-old baby; ${ }^{* *}$ Centre Hospitalier Universitaire Départemental du Borgou; ${ }^{* * *}$ Hôpital de Zone Saint Martin of Papane. 
Table 3. Distribution of characteristics of participants of general population which was the source population of the case series of 2016-2018 epidemics in Tchaourou, Benin.

\begin{tabular}{|c|c|}
\hline Characteristics & $\begin{array}{c}\text { Participants } \\
(\mathrm{N}=172) \\
\mathrm{n}(\%)\end{array}$ \\
\hline Mean Age ${ }^{\star}( \pm \mathrm{SD})$ (years) & $29.9 \pm 8.4$ \\
\hline \multicolumn{2}{|l|}{ Age group } \\
\hline $18-25$ & $68(39.53)$ \\
\hline $26-33$ & $44(25.58)$ \\
\hline $34-41$ & $40(23.26)$ \\
\hline $42-50$ & $20(11.63)$ \\
\hline \multicolumn{2}{|l|}{ Sex } \\
\hline Male & $108(62.8)$ \\
\hline Female & $64(37.2)$ \\
\hline \multicolumn{2}{|l|}{ Occupational status } \\
\hline Civil servants & $8(4.7)$ \\
\hline Farmer & $36(20.9)$ \\
\hline Pupil/student & $16(9.3)$ \\
\hline Craftmen/women & $32(18.6)$ \\
\hline Trader & $52(30.2)$ \\
\hline housewife & $16(9.3)$ \\
\hline other & $12(7.0)$ \\
\hline \multicolumn{2}{|l|}{ Ethnic group } \\
\hline Bariba & $40(23.3)$ \\
\hline Dendi & $28(16.3)$ \\
\hline Fon & $20(11.6)$ \\
\hline Nagot & $40(23.3)$ \\
\hline Peulh & $4(2.3)$ \\
\hline Lokpa/Yom & $8(4.7)$ \\
\hline other & $32(18.6)$ \\
\hline \multicolumn{2}{|l|}{ Religion } \\
\hline Christian & $104(60.5)$ \\
\hline Muslim & $68(39.5)$ \\
\hline \multicolumn{2}{|l|}{ Marital status } \\
\hline Unmarried & $32(18.6)$ \\
\hline Married & $140(81.4)$ \\
\hline \multicolumn{2}{|l|}{ Type of marriage ${ }^{*}$} \\
\hline Monogamous & $104(74.3)$ \\
\hline Polygamous & $36(25.7)$ \\
\hline \multicolumn{2}{|l|}{ Educational level } \\
\hline No Literacy & $64(37.2)$ \\
\hline
\end{tabular}




\section{Continued}

\begin{tabular}{cc}
\hline Primary & $28(16.3)$ \\
Secondary 1 & $36(20.9)$ \\
Secondary 2 & $20(11.6)$ \\
University & $24(14.0)$ \\
Opinion on children' schooling & $160(93.0)$ \\
Good & $12(7.0)$ \\
Bad & \\
Global knowledge on LHF & $20(11.6)$ \\
Acceptable & $32(18.6)$ \\
Insufficient & $120(69.8)$ \\
Poor & \\
\hline
\end{tabular}

*32 missing data.

Table 4. Distribution of the different Directives taken before and during LHF outbreak based on the health workers in Tchaourou, 2018.

Guidelines that have to apply against the epidemic

Participant

$\mathrm{N}=33$

$\mathrm{n}(\%)$

Directives taken before epidemic

Active surveillance of FHL cases

Report of FHL cases

Outreach strategies for detecting FHL cases in community

Systematic directives to children in the commune

Drinking water fetching

Environment, food and clothing hygiene in the community

Existence of practicable road in the commune

Partnership with the commune for job provision to people

Measures for community health empowerment

Involvement of the other sectors to reduce social inequalities in health

Involvement of the community in the decision-making

Organization of periodical sessions for

awareness-raising on infectious diseases prevention

epidemic control Guidelines (during the outbreak)

Automatic transmission of information to authorities

Systematic investigation in the community

Strict follow-up of the set protocol

Systematic alert to the community

Wide raking on the contacts of the case in community 
animals in outbreak period, hunting in the LHF outbreak period, practice of bushfire for the preparation of farms for a new cultivation. Moreover, no health care centre coordination and other sector for improving communities living conditions, no health care centre coordination for hygiene through IEC/BCC, no organization for promoting health in School and market, no habitat regulation to prevent the rodents from entering houses, no implementing of preventive protocol and promoting health at the border of Benin and Nigeria within the outbreak period and so on. In total, the commune had a weak health-promoting environment for fighting against Lassa fever outbreak (Table 5).

Table 5. Results of the evaluation by observation of the components of social determinants in the 5 villages from which LHF cases emerged in the commune of Tchaourou.

\begin{tabular}{|c|c|c|}
\hline Behaviors and lifestyle & Existing & Not existing \\
\hline Consumption of mice & 5 & 0 \\
\hline Consumption of wild animals in outbreak period & 5 & 0 \\
\hline Hunting in the LHF outbreak period & 5 & 0 \\
\hline Practice of bushfire for the preparation of farms for a new cultivation & 5 & 0 \\
\hline Hands washing with water and soap before and after every meal & 2 & 3 \\
\hline $\begin{array}{l}\text { Food hygiene (food protection, good covering of pots, } \\
\text { clean dishes for eating) }\end{array}$ & 0 & 5 \\
\hline Daily food variation & 1 & 4 \\
\hline Clothing Hygiene (cleanness of clothes, clothes without holes in) & 1 & 4 \\
\hline $\begin{array}{l}\text { Hygiene of the living place and neighbourhood (sweeping } \\
\text { of the living place, cleanness of the place of work) }\end{array}$ & 4 & 1 \\
\hline $\begin{array}{l}\text { Touching the body of a person suspected for being } \\
\text { dead of LHF at the time of funerals }\end{array}$ & 0 & 5 \\
\hline \multicolumn{3}{|l|}{ Environment } \\
\hline $\begin{array}{l}\text { Cultural norms (cutting part of the deceased for rites } \\
\text { performing, touching the deceased body for prayer) }\end{array}$ & 5 & 0 \\
\hline Streams & 1 & 4 \\
\hline Drinking water (tap/fountain/very deep wells) & 1 & 5 \\
\hline Places known for hunting & 5 & 0 \\
\hline Passable roads & 2 & 3 \\
\hline Primary/secondary schools & 5 & 0 \\
\hline $\begin{array}{l}\text { School promoting health (well-built buildings, school } \\
\text { canteen, food hygiene, sport space, Infirmary) }\end{array}$ & 0 & 5 \\
\hline Geographic accessibility of schools & 5 & 0 \\
\hline Favorable policy to children's systematic education & 0 & 5 \\
\hline Latrines in every household & 0 & 5 \\
\hline Public latrines & 0 & 5 \\
\hline $\begin{array}{l}\text { Market promoting health (well-built market, always clean, } \\
\text { variation of food product, systematic verification of the expiration } \\
\text { date of products and no trading of the expired products) }\end{array}$ & 0 & 5 \\
\hline
\end{tabular}




\section{Continued}

\begin{tabular}{|c|c|c|}
\hline Policy of the regular collection of garbage/waste & 1 & 4 \\
\hline Social support centres & 1 & 4 \\
\hline Income-generating activity & 5 & 0 \\
\hline Promotion of income-generating activity & 1 & 4 \\
\hline Habitats regulation & 0 & 5 \\
\hline Decentralized private/public structures & 1 & 4 \\
\hline \multicolumn{3}{|l|}{ Health System organization } \\
\hline Health care Centre or village health units & 5 & 0 \\
\hline Health care Centre accessibility & 5 & 0 \\
\hline Health care Centre coordination for directives & 0 & 5 \\
\hline Health care Centre coordination for fetching drinking water & 0 & 5 \\
\hline $\begin{array}{l}\text { Health care Centre coordination for (food, environment } \\
\text { and clothing) hygiene through IEC/BCC }\end{array}$ & 0 & 5 \\
\hline $\begin{array}{l}\text { Health care Centre coordination and other sector for } \\
\text { improving communities living conditions }\end{array}$ & 0 & 5 \\
\hline Delivery of primary health care within the health care centre & 5 & 0 \\
\hline Community relays & 5 & 0 \\
\hline Nigeria and Benin cross-border health care centre & 0 & 1 \\
\hline $\begin{array}{l}\text { Strict protocol to be implemented in case of LHF } \\
\text { outbreak at the border of Nigeria and Benin }\end{array}$ & 0 & 1 \\
\hline $\begin{array}{l}\text { Control of the personal vaccination card before the } \\
\text { Benin-Nigeria border crossing }\end{array}$ & 0 & 1 \\
\hline $\begin{array}{l}\text { Compulsory check of the body temperature for every person } \\
\text { before crossing the Benin-Nigeria border in the outbreak period }\end{array}$ & 0 & 1 \\
\hline
\end{tabular}

\section{Discussion}

In our study, during the year outbreaks of 2016, 2017 and 2018, the commune of Tchaourou recorded 27 cases including 12 confirmed LHF cases when direct observations of various Social determinants of health found that the commune had a weak health-promoting environment for fighting against Lassa fever outbreak in Benin where the index case was always imported from Nigeria, the basic origin of Lassa fever [2] [8] [12] [13]. In this repetitive situation of imported Lassa fever from outside the country, the need for early diagnosis and infection control measures, including use of adequate personal protection equipment (PPE) at every level of contact is required, when highly contagious infections cannot be excluded [14]. In our study, according to the health workers, the post-epidemic guidelines were followed at least at $80 \%$ for each measure. Since 2016, the control measures following has improved in Benin and in 2018, when the first case has been reported the control actions had took place like essentially: all health workers have been orientated in the detection and management of suspected Lassa fever cases; PPE has been supplied to health facilities involved in Lassa fever case management; risk communication and social mobilization ac- 
tivities have been intensified in the affected communities and traditional healers and community leaders have been sensitized on Lassa fever prevention and control measures [7]. Besides the prevention measures, in the context of Benin to control Lassa outbreak, there was delay for mobilizing treatment by ribavirin without laboratory confirmation. Several of symptoms are associated with Lassa fever, ranging from malaise to bleeding gums. These symptoms may be confused with other conditions or diseases and can be overlooked by health workers, and patient is diagnosed late for Lassa. So ribavirin drug was administrated to the confirmed cases very late. This is particularly problematic since ribavirin is at its most effective soon after the appearance of symptoms [4]. But for eradication of LHF, we need beyond prevention and control measures to promote the Social determinants for health. Our study suggests clearly that the severity of the epidemic in Benin was lesser than that of Nigeria. Indeed Olayiwola JO et al. in their study in Nigeria reported for the period between 2015 and 2017 a total of 937 Lassa cases, of which 148 (15.7\%) were confirmed [15]. This difference could be explained by the fact that LHF has been endemic in Nigeria for decades with the persistence of favorable conditions for seasonal outbreaks, unless these conditions become worse where the epidemic episode of 2018 has particularly been rampant in Nigeria compared to previous years since the beginning of the epidemic in 1969. To explain this increase in the Cases of LHF in Nigeria, the scientists made several hypotheses based on the dynamics of the transmission [4] whereas the commune of Tchaourou did not know his first episode of FHL in 2016 with the first case index that had arrived from Nigeria.

In our study, 9 cases were female while 3 were male. Clara Lehmann et al. in Germany in 2016 about an outbreak from imported case found 30 female cases and 25 male cases out of the 55 cases registered [14]. This difference between gender seems justifiable, because the household activity of the woman involves her more in the dynamics of the transmission of the Lassa virus infection especially if it is the contamination of the food by the excrements of the rats. For socio-professional groups, there were 5 housewives, 4 health workers and the daughter of a health worker and 2 traders. Fisher-Hoch S P et al. in Nigeria reported that 34 patients with Lassa fever, including 20 patients, six female nurses, two surgeons, a doctor, and the son of a patient [16]. These results testify to the importance of hospital hygiene that is necessary to adopt as health workers, especially in the developing countries in which the FHL is active.

Of the 12 confirmed cases of FHL recorded, 5 cases had died giving a Case Fatality Rate at $41.6 \%$. Our results corroborate those of Fichet-Calvet E et al. that found among 34 patients with Lassa fever, 22 deaths (65\% Case Fatality Rate) [17]. These results show how often the LHF is serious and testifies to the weakness of the health system in its care. Governments will need to take other prevention-based action through actions on the social determinants of health, community involvement and empowerment in all interventions related to their own health. This can significantly reduce the Case Fatality Rate associated with the LHF even eradicate it. In our study, $100 \%$ of probable cases died while $42 \%$ 
died in confirmed cases. The probable cases mean delays in ribavirin taking. This is particularly problematic since ribavirin is at its most effective soon after the appearance of symptoms [4].

During the outbreak, the automatic alert with field investigation must come first. All contact cases must be followed up for at least 3 weeks. In the hospital, transmission occurs through insufficient infection control measures and non-compliance with the set protocol [18]. Rigorous isolation of cases and procedures requiring body fluids and excrements should be maintained [19]. It is therefore necessary to associate psychological support with both patients and health workers. Haverkort et al. have shown that the use of the matchmaking system, frequent training and information sessions for staff and their relatives can greatly increase the feeling of security and motivation among the staff which leads to in effective care of LHF cases [20]. After the epidemic, it will always be necessary to resume sensitization and especially to check the sustainability of the action taken in community, to see if there has been a change of behavior in the community which will make the interventions sustainable.

Biologically, it should be noted that there is no vaccine so far that can prevent LHF. No study to our knowledge has revealed immunity to LHF nor could a family history of LHF be a risk factor leading to the persistence of LHF. This observation is also made by the Pasteur Institute of France in 2012 [21]. It should be noted that in a study conducted by Pierre Aubry on Lassa fever, it appears that several vaccines are being studied in different countries [22].

In terms of living behavior and habit of the community, it will be necessary to act on the consumption of mice, the practice of hunting in epidemic period, the practice of bushfire, hands washing with water and soap, the hygiene food, hygiene of the living environment. In Togo the study conducted by Patassi et al. reported that the outbreak of LHF was due to the poor living conditions of the community [23]. This result goes in the same direction as ours.

The environment in which the community lives is the second major determinant that needs to be addressed through the systematic education policies of children, the promotion of income-generating activities, the construction of boreholes for drinking water sources, the construction of passable roads, the availability of private/public latrines, the existence of a health promoting school and a health promoting market, the construction of a social support center, the regulation of habitats, the decentralization of private/public structures and the prohibition of cultural norms leading to the appearance of the LHF. In a study conducted by LEE-KWAN SH et al. in Sierra Leone on knowledge, attitude and practice about Ebola in the community, it appears that the concerns of family members about the possibility of seeing the burial, perceptions that bodies have been handled inappropriately, and the fear that stigma may occur if a family member receives a safe and dignified medical burial. Participants suggested that community members have the opportunity to participate in safe and dignified burials would improve community acceptance [24].

The reorganization of the health system through the construction of a 
well-equipped health center for the management of infectious diseases such as the LHF, the accessibility of the health center, the cross-sectoriality between the health center and the other sectors, periodic awareness-raising on LHF, community empowerment, health center construction at the Benin/Nigeria border, protocol follow-up in case of LHF outbreak, verification of vaccination record and body temperature at border are determinants that need to be addressed for the effective control of LHF. Staff should be provided with a pocket guide for the front-line health worker and increased Integrated Disease Surveillance and Response (IDSR) in the commune of Tchaourou [25].

Health promotion, as we have defined it, is based on values including, among others, social justice and equity [26]. This implies for the people the right and the opportunity to participate actively in decisions affecting their health and their life in general. On a national scale, this would justify the option for a political model that promotes the freedom and expression of citizens on decision-making affecting the life of the city. There is no doubt that this model is a democratic model. Wallerstein confirms that the political model that enables community participation and empowerment with a positive impact on health is one where good governance and respect for rights and freedoms are key values [27]. This means that the conditions that must be met by the national political level for the implementation of the concept of health promotion in the fight against the FHL are related to democracy. One of them is the decentralization of the health system in order to take into account the specificity of each context that meets one of the main values of health promotion. In order to go further, people in such a democracy should have the opportunity to ripen solutions to problems in order to allow the central level to take into account the specificities that characterize each region. That said, we are still far from this form of democracy, even though Benin remains a pioneer in this area in Africa as a whole. But with the level of progress of the democratic system in Benin, we are entitled to expect the implementation of a health promotion strategy for the fight against the LHF.

\section{Conclusions}

The fight against infectious diseases, particularly Lassa hemorrhagic fever (LHF), remains a major challenge facing developing countries like Benin.

The communities in which the cases emerge were generally illiterate, of low socio-economic status, and had poor knowledge of LHF, which explains rat consumption practices, poor food and environmental hygiene, and harmful practices that could lead to contamination of the LHF. Since there is no cross-border prevention measure, the commune bordering Nigeria is still susceptible to the outbreak of the Lassa virus epidemic. To fight effectively against the LHF, it is necessary to act on these different social determinants of health with the support of the other sectors while putting at the heart of the actions the community to which one must give the power to make its empowerment. Thus, 
actions and interventions can last in time and will be sustainable.

\section{Conflicts of Interest}

The authors declare no conflicts of interest regarding the publication of this paper.

\section{References}

[1] McCormick, J.B., King, I.J., Webb, P.A., Scribner, C.L. and Craven, R.B. (1986) Lassa Fever. New England Journal of Medicine, 314, 20-26.

https://doi.org/10.1056/NEJM198601023140104

[2] Richmond, J.K. and Baglole, D.J. (2003) Lassa Fever: Epidemiology, Clinical Features, and Social Consequences. BMJ, 327, 1271-1275.

https://doi.org/10.1136/bmj.327.7426.1271

[3] Leparc-Goffart, I. and Emonet, S.F. (2011) An Update on Lassa Virus. MedTrop, 71, 541-545.

[4] Burki, T. (2018) Lassa Fever in Nigeria: The Great Unknown. Lancet, 391, 728. https://doi.org/10.1016/S0140-6736(18)30432-X

[5] Lecompte, E., Fichet-Calvet, E., Daffis. S., Koulemou, K. and Sylla, O. (2006) Mastomys Natalensis and Lassa Fever, West Africa. Emerging Infectious Diseases, 12, 1971-1974. https://doi.org/10.3201/eid1212.060812

[6] Leifer, E., Gocke, D.J. and Bourne, H. (1970) Lassa Fever, A New Virus Disease of Man from West Africa. II. Report of a Laboratory-Acquired Infection Treated with Plasma from a Person Recently Recovered from the Disease. The American Journal of Tropical Medicine and Hygiene, 19, 677-679.

https://doi.org/10.4269/ajtmh.1970.19.677

[7] Organization WHO (2018) Weekly Bulletin on Outbreaks and Other Emergencies. WHO, Geneva, 13-19.

[8] Sambiéni, E.N. and Ridde Valéry, D.N. (2014) La fievre hémorragique à virus lassa au Bénin en en contexte d'Ebola: Une épidémie révélatrice de la faiblesse du système sanitaire. Anthropologie \& Santé, 11, 1-15.

[9] Isere, E.E., Fatiregun, A.A., Ilesanmi, O., Ijarotimi, I. and Egube, B. (2018) Lessons Learnt from Epidemiological Investigation of Lassa Fever Outbreak in a Southwest State of Nigeria December 2015 to April 2016. PLOS Currents, 10. https://doi.org/10.1371/currents.outbreaks.bc4396a6650d0ed1985d731583bf5ded

[10] James, T.O., Akinyemi, A.S.S. and Akinwande, N.I. (2015) Dynamics Transmission of Lassa Fever Disease. International Journal of Innovation and Research in Educational Sciences, 2, 32-36.

[11] United States Agency for International Development (1997) Sampling Guide. http://www.utsc.utoronto.ca/ kmacd/IDSC10/Readings/sampling/sampling

[12] Frame, J.D. (1975) Surveillance of Lassa Fever in Missionaries Stationed in West Africa. Bulletin of the World Health Organization, 52, 593-598.

[13] Frame, J.D., Baldwin, J.M., Gocke, D.J. and Troup, J.M. (1970) Lassa Fever, a New Virus Disease of Man from West Africa: Clinical Description and Pathological Findings. The American Journal of Tropical Medicine and Hygiene, 19, 670-676. https://doi.org/10.4269/ajtmh.1970.19.670

[14] Lehmann, C.K-M., Abdulla, D., Becker, S., Böll, B. and Bunte, A. (2017) Control Measures Following a Case of Imported Lassa Fever from Togo, North Rhine 
Westphalia, Germany, 2016. Eurosurveillance, 22, pii=17-00088. https://doi.org/10.2807/1560-7917.ES.2017.22.39.17-00088

[15] Olayiwola, J.O. and Bakarey, A. (2017) Epidemiological Trends of Lassa Fever Outbreaks and Insights for Future Control in Nigeria. International Journal of Tropical Disease \& Health, 24, 1-14. https://doi.org/10.9734/IJTDH/2017/32823

[16] Fisher-Hoch, S.P., Tomori, O., Nasidi, A., Perez-Oronoz, G.I. and Fakile, Y. (1995) Review of Cases of Nosocomial Lassa Fever in Nigeria: The High Price of Poor Medical Practice. BMJ, 311, 857-859. https://doi.org/10.1136/bmj.311.7009.857

[17] Fichet-Calvet, E. and Rogers, D.J. (2009) Risk Maps of Lassa Fever in West Africa. PLOS Neglected Tropical Diseases, 3, e388. https://doi.org/10.1371/journal.pntd.0000388

[18] World Health Organization (2000) WHO Lassa Fever Fact Sheets No 179.

[19] Cummins, D., McCormick, J.B., Bennett, D., Samba, J.A. and Farrar, B. (1990) Acute Sensorineural Deafness in Lassa Fever. JAMA, 264, 2093-2096. https://doi.org/10.1001/jama.1990.03450160063030

[20] Haverkort, J.J., Minderhoud, A.L., Wind, J.D., Leenen, L.P. and Hoepelman, A.I. (2016) Hospital Preparations for Viral Hemorrhagic Fever Patients and Experience Gained from Admission of an Ebola Patient. Emerging Infectious Diseases, 22, 184-191. https://doi.org/10.3201/eid2202.151393

[21] Institut Pasteur (2012) La fievre Lassa. 6 p.

[22] Aubry, P. and Gauzère, B.A. (2017) Fièvre de Lassa. Médecine tropicale, 1-8.

[23] Patassi, A.A., Landoh, D.E., Mebiny-Essoh Tchalla, A. and Halatoko, W.A. (2017) Emergence of Lassa Fever Disease in Northern Togo: Report of Two Cases in Oti District in 2016. Case Reports in Infectious Diseases, 2017, Article ID: 8242313. https://doi.org/10.1155/2017/8242313

[24] Lee-Kwan, S.H., DeLuca, N., Bunnell, R., Clayton, H.B. and Turay, A.S. (2017) Facilitators and Barriers to Community Acceptance of Safe, Dignified Medical Burials in the Context of an Ebola Epidemic, Sierra Leone, 2014. Journal of Health Communication, 22, 24-30. https://doi.org/10.1080/10810730.2016.1209601

[25] Organisation Mondiale de la Santé (2014) Prise en charge clinique des cas de fièvre hémorragique virale: Guide de poche pour l'agent de santé en première ligne. $113 \mathrm{p}$.

[26] Wise, M. (2007) The Role of Governance in Health Promotion Effectiveness. In: McQueen, D.V. and Jones, C.M., Eds., Global Perspectives on Health Promotion Effectiveness, Springer, New York, 259-278.

[27] Wallerstein, N. (2006) What Is the Evidence on Effectiveness of Empowerment to Improve Health? Who Regional Office for Europe, Copenhagen. http://www.euro.Who.int/document/E88086.pdf 